Revue d'histoire de l'Amérique française

REYUE D.HISTOIRE DE L'AMÉRIQUE FRANÇAISE

\title{
ROCHELEAU-ROULEAU, MADAME CORINNE, Lauréate de \\ l'Académie Française, Laurentian Heritage. Toronto, Longmans Green and Co., 1949. In-12, 178 pages
}

\section{Aristide Beaugrand-Champagne}

Volume 3, numéro 1, juin 1949

URI : https://id.erudit.org/iderudit/801536ar

DOI : https://doi.org/10.7202/801536ar

Aller au sommaire du numéro

Éditeur(s)

Institut d'histoire de l'Amérique française

ISSN

0035-2357 (imprimé)

1492-1383 (numérique)

Découvrir la revue

Citer ce compte rendu

Beaugrand-Champagne, A. (1949). Compte rendu de [ROCHELEAU-ROULEAU, MADAME CORINNE, Lauréate de l'Académie Française, Laurentian Heritage. Toronto, Longmans Green and Co., 1949. In-12, 178 pages]. Revue d'histoire de l'Amérique française, 3(1), 132-133. https://doi.org/10.7202/801536ar d'utilisation que vous pouvez consulter en ligne.

https://apropos.erudit.org/fr/usagers/politique-dutilisation/ 
Rocheleau-Rouleau, Madame Corinne, Lauréate de l'Académio Française, Laurentian Heritage. Toronto, Longmans Green and Co., 1949. In-12, 178 pages. Préface de W.F. Langford, M.A., sans notes, mais avec un petit aperçu biologique de l'auteur. Table des chapitres (VIII) et questionnaire pour chaque chapitre.

Bonne édition, avec reliure commerciale et liseuse montrant une photographie d'un ancien pont couvert en hiver.

Ce livre de madame Corinne Rocheleau-Rouleau est un exposé complet de la vie des Canadiens français dans le cadre naturel de la province de Québec. C'est ainsi que cet ouvrage prend valeur d'histoire et qu'il intéresse la Revue. Sans doute faut-il situer cette vue panoramique dans le temps que l'auteur a choisi elle-même, c'est-à-dire vers 1870; mais il est certain qu'à l'exception de petits détails que la progression de nombreuses découvertes a définitivement retranchés de la vie de notre paysannerie, on pourrait l'appliquer à n'importe quelle paroisse canadienne-française d'aujourd'hui.

Il y a dans ce manuel de folklore - car c'est ainsi que je le vois un désir très net de montrer aux étrangers, sans recours au roman à thèse, et par le simple jeu de faits d'occurrence quotidienne, la douceur de vivre et le bonheur serein de nos gens, bonheur fait de l'acceptation de plein cour d'une condition qu'ils estiment la première et la plus noble de toutes.

Nos compatriotes anglais et les Américains auxquels ce petit livre s'adresse, trouveront à sa lecture un intérêt durable, que les seuls voyages de tourisme n'arriveront jamais à leur procurer. Par le truchement de leur langue qu'elle manie aussi bien que la sienne propre, madame Rouleau fait pénétrer nos voisins dans l'intimité de notre vie et même dans les tréfonds de nos sentiments, dans ce chapitre intitule "Sisters under the skin".

Souhaitons que Laurentian Heritage se répande dans tous les milieux anglophones des États-Unis et du Canada: il y portera sur l'aile de la curiosité d'abord, et ensuite par la réflexion que la lecture entraîne, cette com- 
préhension qui leur a jusqu'ici manqué et les a portés à nous regarder comme a queer people dont la seule passion est de se multiplier sans souci de l'embarras qu'il cause partout où il pénètre.

Sous sa forme de manuel, il fera, je pense, encore plus sûrement le bien que l'on en peut attendre; sa pénétration dans les milieux scolaires trouvera plus facilement le chemin de cette condescendance qu'il faut consentir pour se débarrasser des préjugés qui flattent l'orgueil de race, et font porter des œillères pour ses défauts et des visières pour les qualités d'autrui.

Aristide Beaugrand-Champagne 